\title{
Something Is Like Somebody in Some Way: A Quale Explanation of Verbal Personification
}

\author{
Deyin Long \\ School of Foreign Languages, Sichuan University of Arts and Science, Dazhou, China
}

\section{Email address:}

daniellong2005@sina.com

\section{To cite this article:}

Deyin Long. Something Is Like Somebody in Some Way: A Quale Explanation of Verbal Personification. Communication and Linguistics Studies. Vol. 4, No. 3, 2018, pp. 65-71. doi: 10.11648/j.cls.20180403.11

Received: July 17, 2018; Accepted: July 30, 2018; Published: August 27, 2018

\begin{abstract}
This article takes the Ternary Perspective of Sign Representation in semiotics as its theoretical foundation and constructs quale explanation framework of verbal personification to explain the use mechanism of verbal personification and its quale-sense. Verbal personification contains very rich quale-sense, which is expressed by linguistic symbol and may be perceived in mind by "something is like somebody in some way". Image construction is a critical conscious activity in the forming of verbal personification. Quale explanation is the crucial medium that connects personification and its quale-sense. Quale explanation framework of verbal personification comprehensively interprets the production and comprehension processes of verbal personification.
\end{abstract}

Keywords: Personification, the Ternary Perspective of Sign Representation, Quale, Quale-Sense, Quale Explanation, Image Construction

\section{Introduction}

The use of rhetoric is a conscious activity. It has two kinds of expression deviations: deviation of expression form and that of semantic expression. Personification, one of the semantic rhetoric utterances, belongs to deviation of semantic expression [1], for instance:

(1) John saw the anger of the tempest. [1]

(2) The window winked at me. [2]

In (1), the tempest, or the violent storm, was personified because it could become angry and thus had the ability to express feelings. In (2), the window was attributed the human action "wink". In fact, the inanimate window could never perform any human action. Actions like "wink" could be performed by only human beings. After the window was attributed the human action "wink", it had human flexibility.

Quale has much to do with the foundation of human knowledge and language use [3]. It can be understood by means of analyzing knowledge expression [4]. Personification also has a phenomenon which is similar to quale. It can be presented in the form of quale-sense. This article draws on data of personification from literary works, textbooks or other scholars' works and takes the Ternary Perspective of Sign
Representation (TPSR) in semiotics put forward by Peirce [5] as its theoretical foundation. It focuses on verbal personification, approaches it and its quale-sense from the perspective of quale explanation and seeks to acquire new findings about the study of personification.

\section{Literature Review}

The study of personification has a long and rich tradition which can date back to Erasmus and Quintilian [6]. Personification and allegory are closely related in art and rhetoric studies. Scholars and art historians even use the term "personification allegory" to describe the procedure and result of creating allegory through personification. Melion and Ramakers [7] hold the view, "talking about personification means talking about allegory." According to Whitman [8], personification, or prosopopoeia, refers to the practice of giving a consciously fictional personality to an abstraction and impersonate it. Paxson [9] holds the view that it is only in recent critical and literary theory that personification, or prosopopoeia, has drawn serious attention. It is a readily spotted figure, through which a human identity or "face" is given to something and was automatically equated with allegory for years. 
Within cognitive studies, Lakoff and Johson [10] regard personification as one of the most obvious ontological metaphors in which a physical object is specified as being a person or something nonhuman is seen as human. Along this line, Zhang [2] approaches personification from the perspectives of the Conceptual Metaphor Theory and the Event-domain Cognitive Model. Dorst [6] combines the Metaphor Identification Procedure and Steen's five-step procedure to construct an integral model investigating the different linguistic forms, conceptual structures and communicative functions of verbal personification. Bocarova [11] joins Conceptual Metaphor Theory and findings on the neurocorrelates of aesthetic response together to account for the application of personification in art and literature. Piata and Cánovas [12] focus on time personification in poetic discourse and show that time personification is grounded in Abstract Cause Personification template, in which the cause of an event is mapped onto an agent that performs an action that results in the same event. Liao [1] proposes the Doublet-Structure-of-Consciousness Model (DSCM) to account for the production of semantic rhetoric (including personification) under the Consciousness Theory of the philosophy of mind.

The above-mentioned researches, which have made a lot of contributions to personification studies, vary greatly in nature as they explain personification from different perspectives. Up to now hardly any scholars have ever approached verbal personification from the perspective of quale explanation, nor have they ever paid attention to the quale-sense hidden behind verbal personification. This article approaches verbal personification and its quale-sense from the perspective of quale explanation, aiming to construct quale explanation framework of verbal personification by combining related theories in semiotics, the philosophy of mind and cognitive grammar to explain the use mechanism of verbal personification.

\section{Theoretical Framework}

\subsection{Quale}

Quale, whose plural form is qualia, has been one of the most hotly discussed topics in the philosophy of mind since 1970's. The philosophy of mind focuses on the study of mind, consciousness and their relationship with the body (especially the brain). Peirce was the first philosopher who used terms "quale" and "qualia" in something like its modern sense in 1866. In his opinion, there is a distinctive quale to every combination of sensation. The chief source of the technical use of the term "qualia" is Lewis's discussion in his book Mind and the World Order: Outline of a Theory of Knowledge. Lewis [13] defines quale as a recognizable qualitative character of the given, which may be repeated in different experiences. Quale is directly intuited, given, and purely subjective, and thus it is a sort of universals and must be distinguished from the objective properties of objects in the external world. Objective properties are what people have knowledge of, but people have no knowledge of quale because knowledge always transcends the immediately given. The reasons why Lewis distinguishes qualia from objective properties are that "objective properties are more complex in nature than qualia, and their existence extends beyond the spacious present." [14]. Property dualism put forward by Davidson [15] holds the view that a substance has two kinds of properties: physical property and mental one. The former refers to the property that the substance has in itself. It can be revealed by observations or experiments and can be reduced to itself. The latter refers to the mental feeling that the traits or characters of the substance act on the mind of perceptual subject. It can never be reduced to the substance itself. The phenomenon represented by quale in the philosophy of mind is similar to the mental property of the substance. As Stubenburg [16] notes, "to be conscious is to have qualia." According to Lycan [17], quale is an intentional represented property, the property which experience represents the world as having. Charlmers [18] claims that quale is a kind of conscious experience or a phenomenal property. It refers to the "qualitative" or "phenomenal" feature of conscious states of mind or the subjective character of mental phenomena presented in things. Conscious experience or the phenomenal property has a physical basis. That is to say, quale systematically depends on the physical property. Crane [14] points out that quale is neutral as for the question of whether it is intentional or non-intentional. Crane [19] holds the view that quale is a non-intentional conscious mental property. "A non-intentional mental state is one which has no intentional structure." The stronger form of intentionalism holds the view that all mental states have intentional mental properties. The weak form of intentionalism insists that all mental states are intentional, but some have quale, a non-intentional conscious property or a higher-order property of states of mind. Feser [20] holds the view that quale is not a physical property of the brain, but a non-physical property inhering in its physical substance. Li et al. [21] note that in people's conscious experience, the "for-me" idiosyncrasy of quale is the origin of cognition. Under the effect of quale, the subject's cognitive behaviors get their orientations and meanings. Jiang [4] points out that the issue of quale is a special one about how human beings understand conscious activities, whose root manifests that there is unspeakable or unrepresentable experiential content in everyone's different experiences. Quale involves the mental feeling of human beings and may be perceived in mind by subjective raw feeling of sort of "what it is like to be" [3].

\subsection{Quale and Quale-Sense}

Given that many, varied and conflicting uses to quale have been put [14], it is feasible to apply quale to language studies $[22,23] . \mathrm{Xu}$ and Chen [3] put forward the concept of quale-sense in response to the phenomenon of quale in language use. Quale and quale-sense are homologous. The source of quale-sense is the quale of things. According to the conditioned reflex theory, quale belongs to the category of the first signal system. People's perception of quale reflects the 
sense of phenomenal characters of things, while quale-sense is the sense of phenomenal characters of things represented by linguistic signal system and is related only to the phenomenal character of statements. Quale is mostly reflected on body experience but quale-sense on conceptual experience. Language attributes various senses to people's perceptual organs under the effect of quale-sense of language. Quale-sense is a mental embodiment of readers to the "quale" of "things" depicted in the language. It is based on acquired knowledge, which is essentially unspeakable subjunctive experience or feelings, thus it leads to different readers having infinite explanations of the same thing [24]. Quale-sense is represented by linguistic symbols and may be perceived in mind by "something is like somebody in some way".

\subsection{Quale Explanation and TPSR}

Quale explanation has much to do with TPSR in semiotics. The perspective, which aims to study the sense reference of linguistic signs, is made up of sign or representamen, object and interpretant. According to the perspective, the use of any linguistic sign must involve the three components. Sign or representamen is something that stands for another thing; object is the external thing that sign or representamen directs at; interpretant is the equivalent that sign or representamen presents in the brain as well as the perception, cognition, explanation or evaluation that is made by sign users on the object that sign directs at. Explanation, the structural model that presents in the brain, accounts for the mental reason of an event. It is a kind of virtual existence that reflects mental activities [25]. If the explanation is quale-oriented, quale explanation is the interpretant [22][23]. Quale explanation of verbal personification can be briefly described as follows: verbal personification is the sign or representamen, quale explanation the interpretant and quale-sense the object. Quale explanation framework of verbal personification, the theoretical framework of this article, can be illustrated as figure 1.

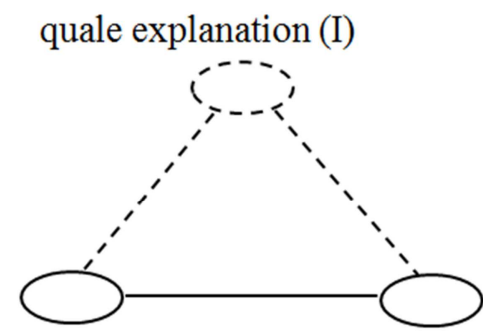

verbal personification $(\mathrm{S} / \mathrm{R})$

quale-sense $(\mathrm{O})$

Figure 1. Quale explanation framework of verbal personification.

In the above explanation framework, verbal personification, quale explanation and quale-sense have made up of a semantic triangle of verbal personification, in which quale explanation is the medium that connects verbal personification to its quale-sense and quale-sense is the reference sense of verbal personification or the object that it directs at. Verbal personification does not have the ability to direct at something.
Instead, linguistic subject has the ability to direct at something and attributes such abilities to linguistic signs. In that case, the study of verbal personification can never ignore linguistic subject, especially his or her mental factors.

\section{Linguistic Realization Means and Semantic Features of Verbal Personification}

\subsection{Linguistic Realization Means of Verbal Personification}

Linguistic realization plays an important role in the identification of verbal personification [6] and the main linguistic realization means of verbal personification depend heavily on the use of verbs, nouns, pronouns, adjectives and adverbs that are suitable for human beings only to describe something, for instance:

(3) The ancient wilderness dreamed, stretched itself all open to the sun, and seemed to sigh with immeasurable content. [26]

(4) I ran across a dim photograph of him the other day, going through some old things. He's been dead twenty-five years. His name was Rex ... and he was a bull-terrier. (James Thurber)

(5) The handsome houses on the street to the college were not fully awake, but they looked very friendly. (Lionel Trilling)

(6) A tree whose hungry mouth is prest against the earth's sweet flowing breast. (Joyce Kilmer, Trees)

(7) The clock on the wall ticked loudly and lazily, as if it had time to spare. [27]

Verbs such as "dream", "stretch" and "sigh" are usually used to describe human beings, but in (3), they were used to describe the ancient wilderness, thus the ancient wilderness was personified and the personification in this example is realized by the use of verbs that are suitable for human beings only to describe the wilderness. In (4), Rex, the bull-terrier, was personified. The personification in this example is realized by the use of the pronouns that are suitable for human beings only to describe the bull-terrier, such as "him", "he" and "his". In (5), the handsome houses were personified by the use of adjectives that are usually used to describe human beings, such as "awake" and "friendly". Example (6) is a verse from Joyce Kilmer's poem Trees. In the example, the tree is personified by the use of both nouns and adjectives that are suitable for human beings only because it can feel thirsty just like a human being and it has a mouth that is pressed against the earth's sweet flowing breast. The earth is also personified because it has a sweet flowing breast. In (7), the author uses the adverbs "loudly" and "lazily" that are suitable for human being only to describe how the clock on the wall ticked, so that the personification in this example is realized by the use of adverbs and the clock on the wall had human characters and states.

\subsection{Semantic Features of Verbal Personification}

Verbal personification has two main semantic features. One 
of them is semantic deviation, which is also known as semantic divergence. It stands for the phenomenon that the semantic expression of a sentence is different from that of an ordinary one because semantic selection restrictions are violated in language use. As verbal personifications are realized by the use of nouns, verbs, pronouns, adjectives and adverbs, their presence will not be established until underlying conceptual structures are analyzed. At the linguistic level, the tension between human beings and non-human objects plays a decisive role [6]. An instance of semantic deviation can be attested in (1), in which the personification is realized by the use of the noun phrase "the anger of the tempest". "Anger" is a strong feeling of displeasure and hostility. Usually human beings or something animate can express anger, while the inanimate tempest or the violent storm can never express anger. In that case, semantic deviation occurs between "anger" and "the tempest". The tempest was personified for the sake of description.

The other semantic feature of verbal personification is frame-shifting. According to Petruck [28], "a frame is any system of concepts related in such a way that to understand any one concept it is necessary to understand the whole system; introducing any one concept results in all of them becoming available." Coulson [29] holds the view that frame-shifting "is semantic reorganization that occurs when incoming information is inconsistent with an initial interpretation". According to double-scope network in conceptual integration theory put forward by Fauconnier and Turner [30], frame-shifting plays an important role in the semantic construction of verbal personification. The two input spaces are organized by different frames, but some topology is projected from both input spaces into the blended space, which produces emergent structure of its own and finally a richer and more specific structure is produced at the end of the integration. Now consider frame-shifting in the semantic construction of the personification in (2). In this network, the frame of the window is in input 1 , in which elements may include: short distance to "me", being very special to "me", and so on. And in input 2 is the frame of "me". Elements in input 2 may include: being close to the window, having a liking for the window for some reason, and so on. The corresponding elements of the two input spaces bear partial mapping relationship and some elements of the two input spaces are projected to the generic space. Projection is an integration of elements from two or more mental spaces. On this basis the elements and an abstract structure in the generic space are produced. Elements in the generic space include the window, "me" and the intimate affection between "us". The abstract structure in the generic space is the existence of intimate affections between the window and "me". Some elements in input spaces and the generic space are discarded while others are projected into the blended space. Meanwhile, frames of both input spaces activate the basic knowledge: inanimate objects can also have human affections or actions. In order to make the window prominent and express its special relationship with "me", the frame of the window was semantically reorganized and the window was endowed with the human action "wink", so a new or emergent structure comes into being in the blended space: the window winked at me.

\section{Image Construction of Verbal Personification}

According to $\mathrm{Xu}$ and Chen [3], information in linguistic expressions can be divided into the following three kinds: literal meaning, implicature, and quale-sense. Mental-physical supervenience is a key dimension for the division of the information in linguistic expressions. Supervenience in philosophy refers to a relation used to describe cases in which a system's upper-level properties are determined by its lower-level ones. Mental-physical supervenience holds the view that "every mental phenomenon must be grounded in, or anchored to, some underlying physical base (presumably a neural state). This means that mental states can occur only in systems that can have physical properties; namely physical systems." [31] When linguistic subject's mental feeling is basically determined by physical event, what language expresses is literal meaning; when linguistic subject's mental feeling can get away from the reliance of physical event to a certain degree and acquire some free will, the linguistic expression can get away from literal meaning to a certain degree and extend towards quale-sense. Implicature is something that lies between literal meaning and quale-sense. Quale-sense, which relies on qualitative attributes of the object depicted in language, is neither the literal meaning of the sentence nor implicature as it is non-deducible. What verbal personification expresses is quale-sense.

One basic assumption of the philosophy of mind and language study is that what language represents is mental representation [32]. According to dual coding theory put forward by Paivio [33], representation is the means by which information presents in the brain. When people process information in the external world, relevant information is represented in the brain. As for the same thing, its processing varies accordingly if it is represented by different means. As dual coding theory is a theory about symbolic systems and has a hierarchical conceptual structure, the general level divides into verbal and nonverbal symbolic subsystems while the lowest level consists of the representational units of each system called logogens and imagens. Language system is peculiar because "it deals directly with linguistic input and output (in the form of speech or writing) while at the same time serving a symbolic function with respect to nonverbal objects, events and behaviors."

$\mathrm{Xu}$ [34] discusses the forming of initial shape of the sentence representation from the viewpoint of the emerging of consciousness. The emerging of sentence representation into the initial shape comes from the emergence of the primary consciousness into reflective consciousness and the forming process of initial shape of the sentence representation is called one of "cutting" the event into the usage event. Event, which includes any social or natural event, lays the foundation of 
sentence representation, while usage event, a symbolic expression assembled in a particular set of circumstances for a particular purpose [35], is what sentence represents. According to $\mathrm{Xu}$ [34], usage event may include the following two stages: pre-language usage event and language usage event. The former refers to the linguistic form of mental representation, which is actually a mental language and presents in the linguistic subject's mind in the form of image, while the latter is the sentence representation. Quale is one of the properties of an event and the event is the "presentation of the given. It is one of the recognizable qualitative characters of the given" [13]. Usually, quale explanation is founded on mental images, while quale-sense is based on special event(s) and verbal personification is a usage event, which is suitable to be used to present the event in this particular situation.

The reason why linguistic expression can attribute different feelings to the sense organs of human beings lies in the effect of quale-sense of linguistic expression. The study of quale-sense of linguistic expression cannot be separated from the study of image because quale-sense of linguistic expression is elicited and presented by specific image [36]. Vocabulary is the carrier of image. Image refers to the fact that vocabulary is likely to arouse certain degree of mental representation. It used to be about mental representation in cognitive psychology. It describes "the occurrence of a perceptual sensation in the absence of the corresponding perceptual input" [35]. Shepard [37] and Kosslyn[38] have pointed out that image is a valid object of rigorous empirical inquiry as status. It can be sensory, visual or auditory, etc. For instance, when people close their eyes, they can evoke a kind of visual sensation by imagining a scene. "Words evoke concepts and concepts in turn designate referents in the projected text world" [6]. Concepts store in the mind in the form of image. Words that are easy to arouse mental representation are called high image words while those that are hard to arouse mental representation are called low image words. High image words usually evoke specific concepts while low image words express abstract concepts [36]. As quale-sense is embodied in linguistic expression, verbal personification lies heavily on image expression, which can be either high or low. Generally speaking, the image of verbal personification presented in the mind contains at least two concepts. One concept is a non-human thing and the other one(s) may be the human action, characteristic or property. The concepts are semantically deviated because of their collocation, but it is just a phenomenon. The truth is that something has been attributed the human action, characteristic or property for the sake of description. Now consider the case in (3). One of the key concepts in this example is the inanimate ancient wilderness. Other concepts in the example, including "dream", "stretch open" and "sigh with content", usually require a human agent. Semantic deviation occurs between concepts in the image. In order to describe how the ancient wilderness came to life, human actions such as "dream", "stretch open" and "sigh with content" were attributed to it and (3) is a verbal personification.

For purposes of thought or expression, image and its derivatives in a third person manner describe people's ability to construe a conceived situation in alternative ways by making use of alternative images [35]. Image construction refers to the structuration of the conceived scene. It is a critical conscious activity and the key point in the forming of a linguistic expression is the forming of mental image [39]. Syntax represents semantics while images symbolize semantics. A syntactic structure, which is closely related to semantics, is the structure of an event. Syntax is event-based and the linguistic expression is image-driven. The use of language is a process of mind from event to usage event, which starts from the linguistic subject's perception of the event(s) in the external world to form primary consciousness. Then it develops into reflective consciousness under the impact of mental-physical supervenience, so perceptual thinking, one of the intuitive thinking patterns, is the basis of image construction. Research on the relationship between image construction and the emergence of the linguistic expression means research on the interface between semantics and syntax [39].

Image construction varies with respect to a lot of parameters. Such variations are referred to as focal adjustments by Langacker [35]. They are focal adjustments of selection, perspective and abstraction respectively. Focal adjustments of selection refer to the process of sifting and extracting information when describing a scene. In the process different cognitive subjects deal with facets of the scene in different ways and that usually leads to different images. Focal adjustments of perspective relate to the positions from which the scene is viewed, and can be understood in terms of figure/ground alignment, viewpoint or subjectivity/objectivity. Focal adjustments of abstraction pertain to the level of specificity at which the situation is portrayed. Different selections, perspectives and abstractions of the cognitive subject lead to different images. The meaning of the linguistic expression, which is not equal to its truth value, is the result of subjective conceptualization.

Image construction of verbal personification does not happen at once and involves focal adjustments of selection, perspective and abstraction as well. Selections of different concepts of verbal personification are made on the basis of physical-mental supervenience, which advocates that language use can neither ignore the influence of mental events nor can be fully determined by physical events. Free will plays a role in image construction of verbal personification. Consider the instance in (4). From the example we know that Rex, a bull-terrier, was selected by the author's free will and described as a person. Focal adjustments of perspective have manifested that the whole example is the ground while pronouns "he", "him" and "his" are the figure. In terms of focal adjustments of abstraction, pronouns such as "he", "him" and "his" are used instead of "it", "it" and "its", making the intimate relationship between Rex and the author more prominent, so in the author's mental image a complex conceptual structure about Rex was established. Image construction is a key point in the forming of verbal personification. 


\section{Verbal Personification and Its Quale-Sense Approached from Quale Explanation}

In quale explanation framework of verbal personification, quale explanation, the interpretant, is actually founded on mental image(s), resulting from the linguistic subject's mental activity. In the subject's mind, a phenomenal quality of something can never be reduced to its physical property. Through association of similarity, a human action, trait or property is attributed to something. Now consider the case in (5), in which "awake" and "friendly" are adjectives. When "awake" is the predicative of a sentence, its agent is usually somebody, who is not asleep, especially immediately before or after sleeping. The same is true for "friendly". When "friendly" is the predicative of a sentence, its agent is usually someone, who behaves in a kind and pleasant way or acts like a friend. It is obvious that the author was deeply impressed by the handsome houses on the street to the college. Through association of similarity human qualities such as being awake and friendly were attributed to the handsome houses. In the author's mind, the handsome houses were like human beings in their state or manner.

Verbal personification is connected to its quale-sense by means of quale explanation. Quale-sense is the manifestation of quale of things depicted in language. It is the linguistic subject's ineffable mental feeling of a conscious object represented by language. It is also the feeling of symbol concepts presented in people's mind. The quale-sense of verbal personification is based on event(s), while verbal personification is a usage event. According to the viewpoint of the emerging of consciousness [34], producing of verbal personification needs to "cut" event into usage event. Quale-sense is the object that the linguistic subject uses verbal personification to direct at, which is also the event that verbal personification relies on. Quale explanation can be regarded as a mental image, and verbal personification is the linguistic usage event.

The production process of verbal personification can be described as follows: quale-sense $\rightarrow$ quale explanation $\rightarrow$ verbal personification. Quale-sense is the foundation of the use of verbal personification as well as the object that linguistic subject wants to direct at by means of verbal personification. In linguistic subject's mind an image emerges that something is like a human being in that they have the same human action, quality or character. After the image is modified by linguistic symbols, verbal personification comes into being. Now consider the version of verbal personification in (6). The quale-sense of the example is based on the event that a tree has roots which need water to grow and are pressed against the earth to suck up moisture from the soil. Through association of similarity, the image emerges in the poet's mind that the tree is like a human being in that they both have mouths. Another image also emerges that the earth is like a mother in that they both have sweet flowing breasts. After such images are fossilized into linguistic symbols, the linguistic usage event or verbal personification has come into being: A tree whose hungry mouth is prest against the earth's sweet flowing breast.

The comprehension process of verbal personification can be described as the following: verbal personification $\rightarrow$ quale explanation $\rightarrow$ quale-sense. When recipients perceive a statement to be a verbal personification, images that something is like a human being in some way emerge in their mind by means of association of similarity. Through quale explanation hearers or readers understand the quale-sense or the object of the verbal personification. Now consider the data in (7). When recipients read or hear the statement and perceive it to be a verbal personification, the image that the way the clock on the wall ticked was like the working manner of a lazy worker in a factory emerges in their mind by means of association of similarity. Through quale explanation, the frame of the clock on the wall was shifted to that of the worker in the factory and recipients finally understand the quale-sense of the verbal personification: the clock on the wall ticked loudly and lazily, just like the worker in the factory talked loudly but worked slowly, as if they had time to spare.

\section{Conclusion}

Personification has attracted the attention of scholars worldwide. Verbal personification is the focal point of study of this article, which takes TPSR in semiotics as its theoretical foundation and approaches verbal personification and its quale-sense from the standpoint of quale explanation. It is found that quale explanation framework of verbal personification comprehensively explains the use mechanism of verbal personification. While explaining how verbal personification is produced and comprehended, enough consideration has been shown for the mental factors of linguistic symbol users, thus the horizon of personification study has been widened. Our analysis does not conflict how personification has been treated in traditional rhetoric, literature, art or cognitive linguistics. Although there seems to have been dispute about quale and even whether there is such a thing as quale at all [14], what is certain is that people can never ignore virtual existence in language studies [25]. Quale explanation, a kind of virtual existence, is a new approach to studies of figurative languages and their quale-sense.

\section{Acknowledgements}

This work was supported by Scientific Research Project Fund of Sichuan Provincial Education Department, China: A Philosophy-of-Mind Study of Personification Expression (No: 18SA0220).

\section{References}

[1] Liao Qiaoyun. (2018). On the Production Mechanism of Semantic Rhetoric. Foreign Language Education, 39(3), $10-14$. 
[2] Zhang Xiao. (2010). Cognitive Interpretation of Personification. Foreign Language and Literature, 26(6), 64-68.

[3] Xu Shenghuan and Chen Xianglan. (2011). Quale and Quale-Sense. Modern Foreign Languages, 33(4), 331-338.

[4] Jiang Yi. (2009). Quale and Knowledge Expression. Social Science Front, 9, 28-34.

[5] Peirce, C. (1931-1958). The Collected Papers of Charles Sanders Peirce, vols.1-8. Cambridge, MA: Harvard University Press.

[6] Dorst, A. G. (2011). Personification in Discourse: Linguistic Forms, Conceptual Structures and Communicative Functions. Language and Literature, 20(2), 113-135.

[7] Melion, W. S. and Ramakers, B. (2016). Personification: Embodying Meaning and Emotion. Leiden / Boston: Brill.

[8] Whitman, J. (1987). Allegory: the Dynamics of an Ancient and Medieval Technique. Cambridge, M A: Harvard University Press.

[9] Paxson, J. J. (1994). The Poetics of Personification. Cambridge: Cambridge University Press.

[10] Lakoff, G. and Johnson, M. (1980). Metaphors We Live by. Chicago: University of Chicago Press.

[11] Bocharova, J. (2016). Personification Allegory and Embodied Cognition. In Melion, W. S. and Ramakers, B. (Eds.), Personification: Embodying Meaning and Emotion (43-69). Leiden / Boston: Brill.

[12] Piata, A. and Cánovas, C. P. (2017). Powerful Rhyme and Sluttish Time: A Cross-linguistic Study of Time Personification in Poetic Discourse. Language and Literature, 26(1), 18-33.

[13] Lewis, C.I. (1929). Mind and the World Order: Outline of a Theory of Knowledge. New York: Dover Publications, Inc.

[14] Crane, T. (2000). The Origins of Qualia. In Crane, T. \& Patterson, S. (Eds.), History of the Mind-Body Problem (1-34). London: Routledge.

[15] Davidson, D. (1980). Mental Events. In Davidson, D. (Ed.), Essays on Actions and Events (207-227). Oxford: Clarendon Press.

[16] Stubenburg, L. (1992).Consciousness and Qualia. Tucson: A doctor's degree thesis of University of Arizona.

[17] Lycan, W. G. (1996). Consciousness and Experience. Cambridge: MIT Press.

[18] Charlmers, D. (1995). Absent Qualia, Fading Qualia, Dancing Qualia. In Metzinger, T. (Ed.), Conscious experience (309-328). Paderborn: Ferdinand Schöningh.

[19] Crane, T. (2001). Elements of Mind: An Introduction to the Philosophy of Mind. Oxford: Oxford University Press.

[20] Feser, E. (2005). Philosophy of Mind: a Beginner's Guide. Oxford: One World Publications.

[21] Li Hengwei, Wang Xiaolu and Tang Xiaowei. (2008). Representation, Qualia and Verbal Thinking. Journal of Zhejiang University (Humanities and Social Sciences), 38(5), 26-33.
[22] Long Deyin. (2014). Quale Explanation of Hyperbole Utterances. Journal of Chongqing University of Posts and Telecommunications (Social Science Edition), 26(6), 169-173.

[23] Long Deyin. (2016). Quale Explanation of Oxymoron. Foreign Language and Literature Research, 2(3), 17-24.

[24] Jiang Yongjun. (2012). On the "Unspeakable" in the Poetic Perceived Effect: A Study of the Quale-Sense to the "Meaning beyond Words". Foreign Language and Literature (Bimonthly), 28(1), 15-18.

[25] Xu Shenghuan. (2012). Focus on Virtual Existence: a Methodological Principle in the Philosophy of Mind and Language Studies. Journal of Hubei University for Nationalities (philosophy and social sciences), 30(5), 129-134.

[26] Feng Cuihua. (2005). A Handbook of English Rhetorical Devices. Beijing: Foreign Language Teaching and Research Press.

[27] Peng Xiao. (2013). A Study on Personification Metaphor Based on Conceptual Integration Theory. Changsha: A master's degree thesis of Hunan Agricultural University.

[28] Petruck, M. (1996). Frame semantics. In Verschueren, J, Östman, J, Blommaert, J, Bulcaen, C. (Eds.) Handbook of pragmatics (1-13). Philadelphia: John Benjamins.

[29] Coulson, S. (2001). Semantic Leaps: Frame-shifting and Conceptual Blending in Meaning Construction. Cambridge: Cambridge University Press.

[30] Fauconnier, G. and Turner, M. (2002). The Way We Think: Conceptual Blending and the Mind's Hidden Complexities. New York: Basic Books.

[31] Kim, J. (2009). Mental causation. In McLaughlin B. P., Beckermann, A., Walter, S., (Eds.), The Oxford Handbook of Philosophy of Mind. Oxford Handbooks Online.

[32] Xu Shenghuan. (2011). Construing Language through Mind-Body Relation: A Philosophy-of-Mind Approach to Language. Journal of Henan University (Social Science), 51(4), $1-12$.

[33] Paivio, A. (1986). Mental Representations. New York: Oxford University Press.

[34] Xu Shenghuan. (2012). From Event to Usage Event: the Forming of the Initial Shape of Sentence Representation. Journal of Henan University (Social Science), 52(4), 137-144.

[35] Langacker, R. (2004). Foundations of Cognitive Grammar, Volume I. Beijing: Beijing University Press.

[36] Liu Hongwei. (2014). The Imagery Expression and Quale-sense of Literary Language. Foreign Language and Literature (Bimonthly), 30(6), 79-85.

[37] Shepard, R. N. (1978). The Mental Image. American Psychologist, 33, 125-137.

[38] Kosslyn, S. M. (1980). Image and Mind. Cambridge, M A:Harvard University Press.

[39] Xu Shenghuan, Li Tian and Hua Hongyan. (2014). Image Building and Syntax Emerging: A Usage-event Based Model for the Research on Syntax-Semantics Interface. Journal of South China University of Technology (Social Science Edition), 16(5), 125-131. 